\title{
Validez en México de los poderes otorgados en el extranjero
}

\section{Randall Emmanuel Villa Gomez}

Notary Public State of Texas randall_emmanuel@hotmail.com

La Secretaria de Relaciones Exteriores reconoce que los Poderes otorgados ante Notario Público Extranjero, para tener validez en México, deberán contener una certificación denominada legalización, en el caso de los países que no formen parte de la Convención de la Haya de 1961 sobre Supresión de Legalizaciones.

Para aquellos países que formen parte de la citada Convención, como México y España, los poderes notariales deben contener la certificación conocida como "apostilla"

En mi ejercicio notarial me he dado cuenta que la practica recurrente de litigantes, notarios e inclusive jueces en Mexico, cuando se encuentran ante la necesidad de un poder notarial que quien deba otorgarlo se encuentra en el extranjero, caso especifico de los Estados Unidos ven como unica opcion el otorgamiento de dicho poder ante el consulado mexicano. Es bien cierto que un consul mexicano esta facultado para actuar en funciones de notario publico conforme a los Articulos 44 Fraccion IV de la Ley del Servicio Exterior Mexicano y 87 de su Reglamento que a letra cito:

“ARTÍCULO 44.- Corresponde a los Jefes de Oficinas Consulares: IV. Ejercer funciones notariales en los actos y contratos celebrados en el extranjero que deban ser ejecutados en territorio mexicano, en los términos señalados por el Reglamento. Su fe pública será equivalente en toda la República, a la que tienen los actos de los notarios en la Ciudad de

1 https://embamex2.sre.gob.mx/espana/index.php/visas/620 pagina consultada el dia 01 de Julio de 2018. 
DERECHO GLOBAL. ESTUDIOS SOBRE DERECHO Y JUSTICIA

México;" ${ }^{2}$

ARTÍCULO 87.- En el ejercicio de las funciones notariales, los Jefes de Oficinas Consulares podrán dar fe, autenticar, protocolizar y revocar contratos de mandato y poderes, testamentos públicos abiertos, actos de repudiación de herencias y autorizaciones que otorguen las personas que ejerzan la patria potestad o la tutela sobre menores de edado incapaces, siempre y cuando dichos actos jurídicos se celebren dentro de su Circunscripción Consular y estén destinados a surtir efectos en México.

Pero tambien es cierto que se omite o desconoce la opcion que podemos encontrar en el Derecho Internacional Privado al que abre la puerta y trae como derecho positivo el articulo 133 de Constitucion Federal de los Estados Unidos Mexicanos que cito:

Artículo 133. Esta Constitución, las leyes del Congreso de la Unión que emanen de ella y todos los tratados que estén de acuerdo con la misma, celebrados y que se celebren por el Presidente de la República, con aprobación del Senado, serán la Ley Suprema de toda la Unión. Los jueces de cada entidad federativa se arreglarán a dicha Constitución, leyes y tratados, a pesar de las disposiciones en contrario que pueda haber en las Constituciones $O$ leyes de las entidades federativas. ${ }^{3}$

Respetuosamente expongo que uno de los antecedentes pocos conocidos o recurridos en el Derecho Internacional Privado en Mexico es la Convención Interamericana sobre Normas Generales de Derecho Internacional Privado, firmada en la ciudad de Montevideo el 8 de mayo de 1979, y publicada en el Diario Oficial de la Federación el 13 de enero de 1983.

Artículo 7. Las situaciones jurídicas validamente creadas en un Estado Parte de acuerdo con todas las leyes con las cuales tengan una conexión al momento de su creación, serán reconocidas en los demás Estados Partes, siempre que no sean contrarias a los principios de su orden público.

2 Fracción reformada DOF 19-04-2018

3 Artículo reformado DOF 18-01-1934, 29-01-2016 
Además, México ratificó tanto el "Protocolo sobre la Uniformidad del Régimen Legal de los Poderes", conocido también como "Protocolo de Washington", el cual fue publicado en el Diario Oficial de la Federación el 3 de diciembre de 1953; así como la "Convención Interamericana sobre el Régimen Legal de los Poderes para ser utilizados en el Extranjero", conocida también como "Convención de Panamá", la cual fue publicada el Diario Oficial de la Federación el día 6 de febrero de 1987. El Protocolo de Washington ha sido suscrito por Bolivia, Brasil, Colombia, El Salvador, México, Nicaragua, Panamá, Estados Unidos de América y Venezuela, y la Convención de Panamá, por Argentina, Bolivia Brasil, Chile, Colombia, Costa Rica, Ecuador, El Salvador, Guatemala, Haití, Honduras, México, Panamá, Paraguay, Perú, República Dominicana, Uruguay y Venezuela.

El Protocolo de Washington señala los requisitos que deben cumplir los poderes que se otorgan en lo Paises que forman parte de la Convension para cual cito integramente el texto de dicho documento:

Articulo 1 En los poderes que se otorgan en los países que forman la Unión Panamericana, destinados a obrar en el extranjero, se observarán las reglas siguientes:

Si el poder lo otorgare en su propio nombre una persona natural, el funcionario que autorice el acto (Notario, Registrador, Escribano, Juez o cualquier otro a quien la ley del respectivo país atribuyere tal función) dará fe de que conoce al otorgante y de que éste tiene capacidad legal para el otorgamiento.

Si el poder fuere otorgado en nombre de un tercero o fuere delegado o sustituido por el mandatario, el funcionario que autorice el acto, además de dar fe, respecto al representante que hace el otorgamiento del poder, delegación o sustitución, de los extremos indicados en el número anterior, la dará también de que él tiene efectivamente la representación en cuyo nombre procede, y de que esta representación es legítima según los documentos auténticos que al efecto se le exhibieren y los cuales mencionará específicamente, con expresión de sus fechas y de su origen o procedencia. 
DERECHO GLOBAL. ESTUDIOS SOBRE DERECHO Y JUSTICIA

Si el poder fuere otorgado en nombre de una persona jurídica, además de la certificación a que se refieren los números anteriores, el funcionario que autorice el acto dará fe, respecto a la persona jurídica en cuyo nombre se hace el otorgamiento, de su debida constitución, de su sede, de su existencia legal actual y de que el acto para el cual se ha otorgado el poder está comprendido entre los que constituyen el objeto o actividad de ella. Esa declaración la basará el funcionario en los documentos que al efecto le fueren presentados, tales como escritura de constitución, estatutos, acuerdos de la Junta u organismo director de la persona jurídica y cualesquiera otros documentos justificativos de la personería que se confiere. Dichos documentos los mencionará el funcionario con expresión de sus fechas y su origen.

Ademas de lo anterior, cito la siguiente tesis de la Suprema Corte de Justicia de la Nación:

PODERES OTORGADOS EN EL EXTRANJERO. PARA QUE SURTAN EFECTOS EN MEXICO CONFORME AL PROTOCOLO SOBRE UNIFORMIDAD DEL REGIMEN LEGAL DE LOS PODERES, NO SON NECESARIOS SU REGISTRO Y PROTOCOLIZACION MIENTRAS NO LO EXIJA UNA LEY FEDERAL ${ }^{4}$. De lo dispuesto por el artículo VII del Protocolo sobre Uniformidad del Régimen Legal de los Poderes del diecisiete de febrero de mil novecientos cuarenta, ratificado por México y publicado en el Diario Oficial de la Federación del tres de diciembre de mil novecientos cincuenta y tres, en el sentido de que los poderes otorgados en el país extranjero no requieren como formalidad previa a su ejercicio la de ser registrados o protocolizados en oficinas determinadas, sin perjuicio de que se practique el registro o la protocolización cuando así lo exija la ley como formalidad especial en determinados casos, se desprende, como regla general, que no son necesarios el registro y protocolización de tales poderes, sino sólo en aquellos supuestos que por sus características particulares, ameriten la observancia de estas formalidades, cuando así lo establezca la ley aplicable en el lugar en donde vaya a ejercerse el poder. En México no existe ninguna ley federal que de manera general y compatible con el Protocolo

4 Octava Epoca: Contradicción de tesis 3/92. Entre las sustentadas por los Tribunales Colegiados Primero y Segundo del Décimo Segundo Circuito. 1o. de marzo de 1994. Mayoría de once votos. NOTA: Tesis P./J.13/94, Gaceta número 78, pág. 44; véase ejecutoria en el Semanario Judicial de la Federación, tomo XIII-Junio, pág. 145

160 Año 3, Número 9, julio- octubre 2018, ISSN 2448-5128 y ISSN-e 24485136 
DERECHO GLOBAL. ESTUDIOS SOBRE DERECHO Y JUSTICIA

establezca los casos en que, para estos efectos, los poderes otorgados en el extranjero deben protocolizarse y registrarse, en cuya razón debe regir la norma general del tratado que libera de la observancia de estas exigencias, sin que sea obstáculo para lo anterior que alguna ley local disponga una regla de eficacia distinta, toda vez que la materia de que se trata es del orden federal, por cuanto atañe a cuestiones jurídicas relativas al tráfico internacional, de modo que no son aplicables al caso las leyes que expidan las legislaturas locales sobre materia notarial o registral.

Se debe cubrir el requisito de autentificar la firma del funcionario ante quien se realizo el poder y para ello debe ser Apostillado o Legalizado como requisito de forma.

Respecto a la Apostilla, se sustenta conforme XII Convension para Suprimir la legalizacion de los documentos publicos extranjeros o conocida como Convension de la Haya sobre Apostilla del 5 de Octubre de 1961 y en su articulo 1, mismo que cito acontinuacion nos menciona que es un requisito para que surta efectos en otro Estado. En el caso en particular entre Estados Unidos y Mexico si forman parte de esta Convención.

Articulo 1.- La presente Convención se aplicará a los documentos públicos que han sido ejecutados en el territorio de uno de los Estados contratantes y que deben ser exhibidos en el territorio de otro Estado contratante. Para fines de la presente Convención, los siguientes serán considerados documentos públicos: c) Actas notariales; $y$,

Por otra parte, si el país de donde se otorgo el poder no es parte de la Convension de Apostilla de la Haya como por ejemplo hasta hace 1 año aproximadamente sucedia con Guatemala, el procedimiento era la legalización consular, sucesiva o en cadena.

No debemos confundir que el sistema de legalización consular fue sustituido por el de apostilla, esto no es así, pues el primero de ellos continúa vigente y se aplica como ya lo mencionaba antes, para los países que no forman parte de la Convención de la Haya.

Para ello, el documento público emitido en el extranjero que pretenda 
tener efectos jurídicos en territorio nacional debe estar legalizado por el sistema consular o de apostilla, según sea el caso, sin este requisito sera impedimento junto con los anteriores para negarle valor al acto notarial realizado. Ya que como ilustra a mayor detalle la siguiente tesis:

PODERES OTORGADOS EN EL EXTRANJERO. ALCANCE DE LA APOSTILLA CUANDO SON VALIDADOS POR UN FUNCIONARIO $P U ́ B L I C O{ }^{5}{ }^{5} \mathrm{El}$ contenido de los artículos 2 a 5 de la Convención por la que se suprime el requisito de legalización de los documentos públicos extranjeros, revela que por regla general, la legalización por parte de la autoridad facultada involucra tres aspectos: a) la autenticidad de la firma; b) la calidad en que el signatario del documento haya actuado; $y$, c) en su caso, la identidad del sello o timbre que el documento ostente; sin embargo, cuando lo actuado por un notario público extranjero al extender el poder general (mandato) fue certificado por un funcionario con fe pública, la apostilla a que se refiere el instrumento internacional en cita, tendría que abarcar sólo a la persona que autenticó el documento notarial en ejercicio de sus atribuciones, pues la certeza alrededor de autenticidad de la firma y facultades del notario derivan de la certificación realizada ante la autoridad extranjera; consecuentemente, así se cumple el trámite de validación única para que el mandato surta sus efectos en territorio nacional que consiste en colocar sobre el propio documento tal apostilla o anotación que certifique la autenticidad de los documentos públicos expedidos en otro país, esto es, la apostilla sólo verificará la autenticidad de la firma del funcionario que certificó el documento notarial, salvo prueba en contrario.

Quiero concluir haciendo mención al argumento más recurrente para tratar de desacreditar los poderes que se otorgan en el extranjero,se menciona que ni siquiera son abogados quienes los realizan, y saben en parte tienen razón, pero con respeto lo digo, si ese fuera el caso, sería la misma situación con los

5 SEGUNDO TRIBUNAL COLEGIADO EN MATERIA CIVIL DEL TERCER CIRCUITO. Amparo en revisión 88/2008. Industrias Alicón, S.A. de C.V. 18 de abril de 2008. 
consulados de México en donde varias de las ocasiones quienes realizan estos poderes tampoco son abogados.

Me dirijo a usted estimado lector y comentarle que me encuentro abriendo brecha y ganándome el respeto como fedatario público ante jueces, notarios públicos, corredores Públicos y litigantes mexicanos e inclusive de otros países de Latinoamerica y Europa, llenándome el pecho de orgullo al decirles soy Abogado por la Universidad de Guadalajara en Jalisco México y también Profesor de dicha Universidad. 
